\title{
Ibuprofen Versus Continuous Indomethacin in Premature Neonates With Patent Ductus Arteriosus: Is the Difference in the Mode of Administration?
}

\author{
CATHY HAMMERMAN, IRENA SHCHORS, STEFAN JACOBSON, MICHAEL S. SCHIMMEL, RUBEN BROMIKER, \\ MICHAEL KAPLAN, AND AMIRAM NIR

\begin{abstract}
Department of Neonatology [C.H., I.S., S.J., M.S.S., R.B., M.K., A.N.]; Faculty of Medicine [C.H., M.S.S., M.K.];
\end{abstract} \\ Department of Pediatric Cardiology [A.N.], Hebrew University of Jerusalem, Jerusalem 91031 Israel
}

\begin{abstract}
Ibuprofen has been proposed as a preferential alternative to indomethacin in treating patent ductus arteriosus (PDA), because it is purported to have less renal, mesenteric, and cerebral vasoconstrictive effects. However, short and long-term safety concerns regarding ibuprofen remain. Continuous slow infusion of indomethacin also eliminates peripheral vasoconstriction and may thus offer similar benefits to ibuprofen without safety concerns. In this study, our objective was to show that treating a PDA with continuous indomethacin is similar to ibuprofen in its effect on urine output, renal function, and blood flow velocities in the renal, superior mesenteric, and anterior cerebral arteries. Sixty four prematures with PDA were randomly, prospectively assigned to either treatment. PDA closure rates were similar (74 versus 59\%; $p=0.123$ ). Nine indomethacin-treated babies (29\%) versus twelve ibuprofen babies $(38 \%)$ underwent repeated therapy $(p=0.656)$. Two indomethacin and four ibuprofen infants required surgical ligation $(p=0.672)$. Serum creatinine, oliguria, estimated glomerular filtration rate, and fractional excretion of sodium were similar in both groups, as were blood flow velocity parameters in the vessels studied. There were no differences in necrotizing enterocolitis, BPD, intraventricular hemorrhage, and/or retinopathy of prematurity. In conclusion, PDA treatment with either continuous indomethacin infusion or ibuprofen was equally devoid of adverse renal effects and/or peripheral vasoconstrictive effects. (Pediatr Res 64: 291-297, 2008)
\end{abstract}

$\mathrm{A}$ lthough patency of the ductus arteriosus is functionally essential for fetal circulation, persistent postnatal ductal patency may have adverse hemodynamic effects, necessitating therapeutic intervention. Indomethacin has been shown to successfully mediate ductal closure in approximately $70 \%$ of treated patent ductus arteriosus (PDA), and, until recently, it has constituted the mainstay of medical therapeutic closure.

However, treatment with indomethacin, classically administered as a bolus injection, can cause vasoconstriction, albeit transient, of peripheral vascular beds resulting in reduced organ perfusion and potentially undesirable side effects (1-4). Because it purportedly lacks these side effects, ibuprofen has been proposed as a pharmacologically similar, but therapeutically preferential alternative in the treatment of PDA (5-11). Ibuprofen is also a cyclooxygenase inhibitor, which seems to

Received December 4, 2007; accepted April 18, 2008

Correspondence: Cathy Hammerman, M.D., Department of Neonatology, POB 3235,

Shaare Zedek Medical Center, Jerusalem, Israel 91031; e-mail: cathy@cc.huji.ac.il

Supported by the Hammerman-Fisch Foundation. be equally effective in mediating ductal closure, while minimizing adverse renal effects (11). It has also been reported to have fewer vasoconstrictive side effects $(7,8,11)$ compared with bolus indomethacin. However, both the absence of longterm safety data and uncertainties regarding short-term safety of ibuprofen, including possible interference with bilirubin albumin binding and an increased risk of necrotizing enterocolitis (NEC) and pulmonary hypertension (with ibuprofen tris-hydroxyamino-methane [12]) remain of concern.

In a previous study (13), we demonstrated that continuous 36-h infusion of indomethacin virtually eliminated the reduction in cerebral blood flow velocity observed with bolus infusions. Furthermore, renal side effects, such as oliguria and elevated serum creatinine, which often accompany bolus indomethacin, did not occur. Christmann et al. (14) confirmed and extended these observations, demonstrating that reductions in mesenteric and renal flow velocities associated with bolus indomethacin were also prevented by continuous infusion.

Although ibuprofen has been compared with conventionally administered (bolus) indomethacin, it has not, to date, been compared with indomethacin administered by continuous infusion. Furthermore, none of the studies to date has looked at the combined effect of treatment on both renal function and peripheral blood flow velocity parameters. Because the proposed advantage of ibuprofen over indomethacin has been attributed to its reduction of adverse renal effects, we hypothesized that indomethacin given by continuous infusion would provide equivalent protection to that offered by ibuprofen in treating PDA in that it also eliminates renal and other vasoconstrictive side effects.

Specifically, our primary objective was to demonstrate that there are no differences in urine output and/or serum creatinine between those treated with continuous indomethacin infusion and those treated with ibuprofen. As secondary objectives, we sought to demonstrate that the two treatments do not differ in their effect on renal, superior mesenteric, and anterior cerebral artery blood flow velocity or on the incidences of longer term clinical outcomes, which potentially have a vascular-mediated component, e.g. NEC, intraventricular hemorrhage (IVH) or retinopathy of prematurity (ROP).

Abbreviations: NEC, necrotizing enterocolitis; PDA, patent ductus arteriosus 


\section{PATIENTS AND METHODS}

Inborn premature neonates ( $\mathrm{GA} \leq 33$ wks, $\mathrm{BW} \leq 1750 \mathrm{~g}$ ) admitted to the neonatal intensive care unit of Shaare Zedek Medical Center were potential candidates for the study. Babies with additional congenital heart lesions, documented infection, thrombocytopenia $(<60,000)$ or IVH grade 4 were excluded. The study was approved by the Helsinki committee of Shaare Zedek and registered on the clinical trials registry web site. In our unit, ventilated low birth weight infants are routinely studied by a pediatric cardiologist between 36 and $72 \mathrm{~h}$ of life using 2D echocardiography with color flow mapping to assess ductal patency. Once the parental consent was obtained, ventilated infants with left to right ductal shunting were assigned to either

Continuous indomethacin (Indocin, Merck \& Co., West Point, PA, USA) diluted in normal saline and infused continuously for $36 \mathrm{~h}$ at a rate of 17 $\mu \mathrm{cg} / \mathrm{kg} / \mathrm{h}$ or

Ibuprofen lysine (Arfen, Lisapharma, Erba Co., Italy) diluted in sterile water and infused over $15 \mathrm{~min}$ with an initial dose of $10 \mathrm{mg} / \mathrm{kg}$ followed by two doses of $5 \mathrm{mg} / \mathrm{kg}$ at $24-\mathrm{h}$ intervals.

Randomization was based on computer-generated random numbers without substratification. Because the methods of drug administration were clearly different, the study could not be double blinded. However, the cardiologist, performing the echocardiograms, was blinded to the study group. The study involved only one therapeutic course. Babies who did not respond to this initial course of therapy were treated by their physicians according to clinical judgment. All infants were followed with serial echocardiographic examinations until eventual PDA closure or hospital discharge.

Study outcomes. Treatment outcome was coded as complete closure $=1$, constriction without complete closure $=2$, no response $=3$, and surgical ligation $=4$.

Renal function. Quantitative urine output, serum and urine electrolytes, including creatinine were recorded daily during the study. Acute renal failure was defined as urine output of $<1 \mathrm{~mL} / \mathrm{kg} / \mathrm{h}$ and/or an increase in serum creatinine of $\geq 0.2 \mathrm{mg} / \mathrm{dL}$. Fractional excretion of sodium (FENa) was calculated using a standard formula as follows:

$$
\operatorname{FENa}(\%)=(\mathrm{UNa} \times \mathrm{Scr}) /(\mathrm{UCr} \times \mathrm{SNa}) \times 100
$$

where UNa indicates urinary sodium concentration $(\mathrm{mg} / \mathrm{dL})$; Scr, serum creatinine $(\mathrm{mg} / \mathrm{dL})$; Ucr, urinary creatinine $(\mathrm{mg} / \mathrm{dL}) ; \mathrm{SNa}$, serum sodium (mg/dL).

Glomerular filtration rate (GFR) was estimated using a modified Schwartz equation:

GFR $\left(\mathrm{mL} / \mathrm{min} / 1.73 \mathrm{~m}^{2}\right)=k \times$ length $(\mathrm{cm}) /$ serum creatinine $(\mathrm{mg} / \mathrm{dL})$

where $k$ is the constant (0.33 in premature infants) (15).

Blood flow velocities. Flow velocity was assessed by pulsed Doppler ultrasonography (Hewlett Packard Image Point Ultrasound System, Andover, MA, USA), using a 7.5-MHz transducer with an insonation angle close to $0^{\circ}$, a sample volume of $1.5 \mathrm{~mm}$ and a $100-\mathrm{Hz}$ high pass filter to reduce noise, and with infants were supine. Peak systolic velocity (SV), end-diastolic velocity (DV), and velocity time integral (VTI $=$ the area under the curve) were recorded. Resistance index $(\mathrm{RI}=(\mathrm{SV}-\mathrm{DV}) / \mathrm{SV})$ was calculated. For each measurement, two consecutive high-quality waveforms were averaged for each patient/time. Clinicians were blinded to the results of Doppler studies.

SMA. The transducer was positioned on the midabdomen just above the umbilicus in the sagittal plane. Babies were not fed during the study period. Doppler sample volume was placed in the proximal portion of the artery near its origin from the aorta.

Right renal artery. The transducer was positioned below the costal margin in the dorsolateral area of the right flank. The longest possible segment of artery was examined, and the sample volume was kept as small as possible $(1 \mathrm{~mm})$. The flow velocity waveforms were obtained at an insonating angle of less than $30^{\circ}$.

Right anterior cerebral artery. Open fontanelles and sutures of the newborn provide unique windows for cranial ultrasound neuroimaging. The transducer was positioned on the fontanellar region, in the sagittal plane, and the artery was insonated at its curve around the corpus callosum.

Long-term outcome. Our unit routinely records detailed information on all neonates of $\leq 1500$-g birth weight. The background incidence of NEC, IVH, and ROP is presented from this data. Of note, because our study population includes infants of $\leq 1750$-g birth weight, the incidence of these entities would be expected to be lower in the study population than the background incidence.

Data analysis. Data were analyzed using SigmaStat 3.0 (SPSS). Intergroup variations for continuous variables were analyzed using repeated measures
ANOVA followed by Newman Keuls test or the Friedman repeated measures analysis of variance on ranks if data were nonparamatric. Intragroup variations were analyzed at each time point using analysis of variance. Nonparametric variables are presented as median (25\% ile, $75 \%$ ile) and were compared using the Mann-Whitney rank sum test. Categorical variables were analyzed using a $\chi^{2}$ test. Significance was accepted as $p<0.017$, given the Bonferroni correction for multiple comparisons. We calculated that a total of 36 patients, 18 in each treatment arm, would be needed to demonstrate that continuous indomethacin has a "noninferior" effect on urine output at $48 \mathrm{~h}$. For purposes of calculating sample size, the limit of noninferiority was defined as a urine output similar to within $1 \mathrm{~mL} / \mathrm{kg} / \mathrm{h}$ in the two groups, assuming an $\alpha=0.20$ and $\beta=0.05$.

\section{RESULTS}

Patient characteristics. Sixty-four babies with PDA were recruited between February 2002 and December 2006. Thirtyone were randomized to continuous indomethacin and 33 to ibuprofen. One baby assigned to the ibuprofen group was withdrawn by his parents before he started therapy, and he has not been included in the analysis. No baby who expired did so during the intervention phase of the study; thus, all other babies who entered the study received a full course of therapy. There were no differences between the two study groups at baseline (Table 1).

PDA-related parameters. There were no significant differences in PDA responsiveness to therapy between groups (Figs. $1 \mathrm{~A}$ and $\mathrm{B})$. The ductus was completely closed in $23(74 \%)$ continuous indomethacin treated babies versus 19 (59\%) ibuprofen-treated babies $(p=0.132)$. Four indomethacin versus two ibuprofen babies, who initially closed their PDA, subsequently developed recurrences. All these responded to a repeat course of therapy. Two indomethacin versus eight ibuprofen babies showed no ductal response to initial treatment $(p=$ 0.082 ). The remaining infants showed different degrees of partial ductal constriction without complete closure.

When babies $\leq 27 \mathrm{wk}$ were analyzed separately, $71 \%$ of the indomethacin babies closed, $7 \%$ showed no response, and $22 \%$ showed ductal vasoconstriction without complete closure. Of those treated with ibuprofen, $47 \%$ closed, $32 \%$ showed no response, and $21 \%$ showed ductal vasoconstriction without complete closure. There was no difference $(p=$ 0.214 ) in the response to treatment among $\leq 27$ weekers.

The mean pretreatment ductal diameters were $2.04 \pm 0.86 \mathrm{~mm}$ versus $1.96 \pm 1.06 \mathrm{~mm}$ in the indomethacin and ibuprofen groups, respectively; $p=0.795$. PDA diameter pretreatment did

Table 1. Baseline patient characteristics

\begin{tabular}{lccc}
\hline & $\begin{array}{c}\text { Continuous } \\
\text { indomethacin } \\
(n=31)\end{array}$ & $\begin{array}{c}\text { Ibuprofen } \\
(n=32)\end{array}$ & Significance $(p)$ \\
\hline Birth weight (kg) & $1.10 \pm 0.45$ & $1.06 \pm 0.35$ & 0.626 \\
Gestational age (wks) & $27.8 \pm 2.8$ & $27.8 \pm 2.6$ & 0.885 \\
$\quad$ Male:female & $18: 13$ & $14: 18$ & 0.377 \\
$\quad$ Day of life treated & $4.5[2.3,7.7]$ & $3.7[2.5,5.5]$ & 0.504 \\
$\quad$ Baseline (BL) $\mathrm{FiO}_{2}$ & $34 \% \pm 13 \%$ & $32 \% \pm 14 \%$ & 0.556 \\
$\quad \begin{array}{l}\text { BL oxygenation } \\
\quad \text { index }\end{array}$ & $4.2 \pm 2.6$ & $4.6 \pm 4.1$ & 0.643 \\
BL fluid intake & $154 \pm 38$ & $151 \pm 55$ & 0.748 \\
$\quad(\mathrm{cc} / \mathrm{kg} /$ day) & & & \\
BL urine output & $5.1 \pm 2.2$ & $4.8 \pm 2.1$ & 0.579 \\
$\quad(\mathrm{cc} / \mathrm{kg} / \mathrm{hr})$ & & & \\
$\quad$ Mortality & 4 & 3 & 0.708 \\
\hline
\end{tabular}




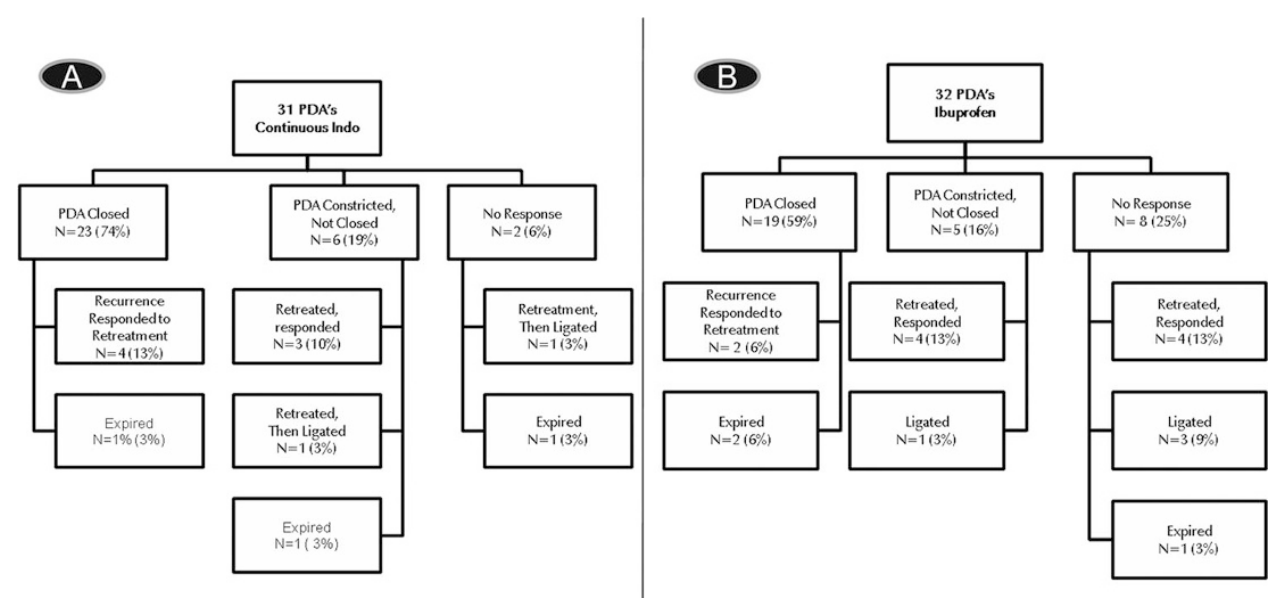

Figure 1. (A) PDA outcomes in continuous indomethacin treated infants. (B) PDA outcomes in ibuprofen treated infants. not correlate with coded treatment outcome, although there seems to be a trend in this direction $(p=0.052)$. Larger PDA diameter pretreatment was, however, strongly correlated with the number of courses of treatment given $(p=0.006)$.

In total, 9 indomethacin babies (29\%) versus 12 ibuprofen babies $(38 \%)$ underwent repeated therapy $(p=0.656)$. Six of the $64(9.4 \%)$ total study infants eventually underwent surgical ductal ligation after failure of repeated attempts at medical closure. Two of these were from the continuous indomethacin group and four from the ibuprofen group $(p=0.672)$. The mean gestational age of those ligated was $25.17 \pm 0.81 \mathrm{wk}$, which was significantly less than $28.02 \pm 0.64 \mathrm{wk}$, the mean gestational age of the remaining babies (both groups) who did not require surgical ligation $(p \leq 0.001)$. Their birth weights were $703 \pm 110 \mathrm{~g}$ versus $1110 \pm 410 \mathrm{~g}$ ( $p \leq 0.001)$, respectively. They were treated on $4.7 \pm 1.9$ versus $5.2 \pm 4.7 \mathrm{~d}$ of life $(p=0.798)$. Of note, no baby whose ductus closed completely after the first round of therapy, either with drug, proceeded to surgical ligation. Because the numbers are small and there does not seem to be any difference between the indomethacin versus ibuprofen groups with respect to age or size of the infants, the ligated infants from both groups have been combined for these analyses only.

Effect of treatment on renal function. None of the infants in either of the group developed acute renal failure during the study defined as a decrease in urine output of $\geq 1 \mathrm{~mL} / \mathrm{kg} / \mathrm{h}$ or an increase in serum creatinine of $\geq 0.2 \mathrm{mg} / \mathrm{dL}$. Additional renal function parameters are presented in Table 2. Although there were some changes noted with treatment within each of the groups, there were no significant differences between the groups in any of the renal parameters studied at any point of time during the study.

Right renal flow velocity. Table 3 presents right renal flow velocity parameters for both groups over time. There were no significant differences between the treatment groups in the mean values for any parameter at any given time, other than a transient decrease in systolic flow velocity (SFV) at $1 \mathrm{~h}$ in the ibuprofen group. There were 9 individual indomethacin and 10 ibuprofen infants whose renal SFV decreased by $>50 \%$. Nevertheless, none of these infants was clinically symptomatic, i.e., no decrease in urine output and no increase in creatinine levels.
Superior mesenteric flow velocity. Table 4 presents SMA flow velocity parameters for both groups over time. RI was decreased in the continuous indomethacin group at $48 \mathrm{~h}$. Small increases in diastolic flow velocity were observed with ductal closure, not significant in either group. There were no significant differences between the treatment groups for any parameter at any given time.

Right anterior cerebral flow velocity. Table 5 presents the right anterior cerebral flow velocity parameters for both groups over time. There was an increase in diastolic velocity

Table 2. Renal parameters

\begin{tabular}{|c|c|c|c|}
\hline & Indomethacin & Ibuprofen & $\begin{array}{c}\text { Significance } \\
\text { [indo vs ibu] } \\
(p)\end{array}$ \\
\hline \multicolumn{4}{|l|}{ Current weight (kg) } \\
\hline Pre-treatment & $0.83[0.68,1.32]$ & $0.85[0.73,1.15]$ & 0.82 \\
\hline $24 \mathrm{hr}$ & $0.83[0.71,1.27]$ & $0.86[0.72,1.16]$ & 0.85 \\
\hline $48 \mathrm{hr}$ & $0.88[0.78,1.33]$ & $0.89[0.71,1.14]$ & 0.84 \\
\hline \multicolumn{4}{|l|}{$\begin{array}{l}\text { Mean blood pressure } \\
(\mathrm{mm} \mathrm{Hg})\end{array}$} \\
\hline Pre-treatment (BL) & $39 \pm 5$ & $40 \pm 8$ & 0.31 \\
\hline $24 \mathrm{hr}$ & $43 \pm 7$ & $44 \pm 7$ & 0.93 \\
\hline $48 \mathrm{hr}$ & $46 \pm 9$ & $45 \pm 10$ & 0.98 \\
\hline \multicolumn{4}{|l|}{ Urine output (cc/kg/hr) } \\
\hline Pre-treatment & $5.1 \pm 2.3$ & $4.8 \pm 2.1$ & 0.70 \\
\hline $24 \mathrm{hr}$ & $5.5 \pm 1.6$ & $4.8 \pm 2.0$ & 0.71 \\
\hline $48 \mathrm{hr}$ & $5.1 \pm 1.9$ & $4.7 \pm 1.6$ & 0.11 \\
\hline \multicolumn{4}{|l|}{ Creatinine (mg/dL) } \\
\hline Pre-treatment $(\mathrm{BL})$ & $0.85 \pm 0.18$ & $0.84 \pm 0.22$ & 0.53 \\
\hline $24 \mathrm{hr}$ & $0.81 \pm 0.17$ & $0.81 \pm 0.22$ & 0.50 \\
\hline $48 \mathrm{hr}$ & $0.81 \pm 0.1$ & $0.78 \pm 0.23$ & 0.40 \\
\hline \multicolumn{4}{|l|}{$\begin{array}{l}\text { Schwartz GFR } \\
\qquad\left(\mathrm{mL} / \mathrm{min} / 1.73 \mathrm{~m}^{2}\right)\end{array}$} \\
\hline Pre-treatment (BL) & $14.7 \pm 3.5$ & $14.7 \pm 3.3$ & 1.00 \\
\hline $24 \mathrm{hr}$ & $15.4 \pm 3.9$ & $15.4 \pm 3.9$ & 0.72 \\
\hline $48 \mathrm{hr}$ & $15.6 \pm 3.7$ & $16.0 \pm 4.2$ & 0.80 \\
\hline \multicolumn{4}{|l|}{$\mathrm{FeNa}(\%)$} \\
\hline Pre-treatment & $3.9 \pm 2.5 \%$ & $4.5 \pm 2.9 \%$ & 0.94 \\
\hline $24 \mathrm{hr}$ & $4.1 \pm 2.3 \%$ & $3.5 \pm 1.8 \%$ & 0.21 \\
\hline $48 \mathrm{hr}$ & $3.6 \pm 1.9 \%$ & $3.5 \pm 1.8 \%$ & 0.11 \\
\hline \multicolumn{4}{|l|}{ Serum sodium $(\mathrm{mg} / \mathrm{dL})$} \\
\hline Pre-treatment & $137[133,140]$ & $139[135,142]$ & 0.23 \\
\hline $24 \mathrm{hr}$ & $139[134,143]$ & $136[134,140]$ & 0.79 \\
\hline $48 \mathrm{hr}$ & $138[136,140]$ & $137[135,139]$ & 0.34 \\
\hline
\end{tabular}


Table 3. Renal blood flow velocity

\begin{tabular}{|c|c|c|c|}
\hline $\begin{array}{l}\text { Right renal } \\
\text { artery }\end{array}$ & Indomethacin & Ibuprofen & $\begin{array}{c}\text { Significance } \\
\text { indomethacin vs. } \\
\text { ibuprofen }(p)\end{array}$ \\
\hline \multicolumn{4}{|l|}{$\begin{array}{l}\text { Systolic velocity } \\
(\mathrm{cm} / \mathrm{sec})\end{array}$} \\
\hline Pre-treatment & $40[25,54]$ & $39[23,50]$ & 0.58 \\
\hline $1 \mathrm{hr}$ & $36[25,53]$ & $28[21,36]$ & 0.03 \\
\hline $24 \mathrm{hr}$ & $34[25,39]$ & $29[23,33]$ & 0.89 \\
\hline $48 \mathrm{hr}$ & $41[22,52]$ & $34[21,50]$ & 0.67 \\
\hline \multicolumn{4}{|l|}{$\begin{array}{l}\text { Diastolic velocity } \\
(\mathrm{cm} / \mathrm{sec})\end{array}$} \\
\hline Pre-treatment & $2.4[1.5 .3 .8]$ & $2.2[1.3 .2 .6]$ & 0.60 \\
\hline $1 \mathrm{hr}$ & $2.1[1.4 .4 .1]$ & $1.7[3.4,2.2]$ & 0.05 \\
\hline $24 \mathrm{hr}$ & $2.2[1.5,3.3]$ & $2.1[1.2,4.3]$ & 0.44 \\
\hline $48 \mathrm{hr}$ & $3.3[1.8,5.9]$ & $2.9[1.6,4.5]$ & 0.63 \\
\hline \multicolumn{4}{|l|}{$\begin{array}{c}\text { Velocity time } \\
\text { integral }\end{array}$} \\
\hline Pre-treatment & $4.8 \pm 3.4$ & $4.5 \pm 2.6$ & 0.90 \\
\hline $1 \mathrm{hr}$ & $4.9 \pm 3.2$ & $3.8 \pm 2.1$ & 0.30 \\
\hline $24 \mathrm{hr}$ & $4.9 \pm 2.0$ & $4.5 \pm 2.5$ & 0.21 \\
\hline $48 \mathrm{hr}$ & $4.2 \pm 3.4$ & $5.2 \pm 3.2$ & 0.12 \\
\hline \multicolumn{4}{|l|}{ Resistance index } \\
\hline Pre-treatment & $0.93[0.90,0.97]$ & $0.92[0.90,0.96]$ & 0.73 \\
\hline $1 \mathrm{hr}$ & $0.94[0.91,0.95]$ & $0.92[0.87,0.96]$ & 0.46 \\
\hline $24 \mathrm{hr}$ & $0.92[0.89,0.96]$ & $0.92[0.88,0.96]$ & 0.95 \\
\hline $48 \mathrm{hr}$ & $0.91[0.83,0.94]$ & $0.92[0.85,0.96]$ & 0.88 \\
\hline
\end{tabular}

Values are presented as means \pm standard deviation when appropriate or as median [interquartile range] when the distribution was not normal. There were no significant differences between the groups. $[\mathrm{P}<0.017$ would represent a significant difference between treatment groups taking into account Bonferroni adjustment for multiple measurements.]

Table 4. Superior mesenteric artery flow velocity

\begin{tabular}{|c|c|c|c|}
\hline $\begin{array}{c}\text { Superior mesenteric } \\
\text { artery }\end{array}$ & Indomethacin & Ibuprofen & $\begin{array}{c}\text { Significance } \\
\text { indomethacin vs. } \\
\text { ibuprofen }(p)\end{array}$ \\
\hline \multicolumn{4}{|l|}{$\begin{array}{l}\text { Systolic velocity } \\
(\mathrm{cm} / \mathrm{sec})\end{array}$} \\
\hline Pre-treatment & $40 \pm 25$ & $32 \pm 19$ & 0.29 \\
\hline $1 \mathrm{hr}$ & $40 \pm 26$ & $28 \pm 17$ & 0.12 \\
\hline $24 \mathrm{hr}$ & $40 \pm 26$ & $34 \pm 18$ & 0.34 \\
\hline $48 \mathrm{hr}$ & $43 \pm 32$ & $37 \pm 30$ & 0.34 \\
\hline \multicolumn{4}{|l|}{$\begin{array}{l}\text { Diastolic velocity } \\
\qquad(\mathrm{cm} / \mathrm{sec})\end{array}$} \\
\hline Pre-treatment & $2.2[1.3,3.2]$ & $1.8[1.3,2.9]$ & 0.27 \\
\hline $1 \mathrm{hr}$ & $2.7[1.5,5.0]$ & $2.2[1.2,3.9]$ & 0.32 \\
\hline $24 \mathrm{hr}$ & $2.6[1.3,5.0]$ & $2.3[1.7,3.9]$ & 0.94 \\
\hline $48 \mathrm{hr}$ & $2.9[1.9,7.0]$ & $2.9[1.9,5.3]$ & 0.79 \\
\hline \multicolumn{4}{|l|}{$\begin{array}{c}\text { Velocity time } \\
\text { integral }\end{array}$} \\
\hline Pre-treatment & $5.0 \pm 4.2$ & $3.8 \pm 2.5$ & 0.48 \\
\hline $1 \mathrm{hr}$ & $5.1 \pm 4.5$ & $3.5 \pm 2.4$ & 0.20 \\
\hline $24 \mathrm{hr}$ & $5.8 \pm 4.9$ & $3.9 \pm 2.1$ & 0.33 \\
\hline $48 \mathrm{hr}$ & $6.3 \pm 6.6$ & $4.6 \pm 3.1$ & 0.27 \\
\hline \multicolumn{4}{|l|}{ Resistance index } \\
\hline Pre-treatment & $0.93 \pm 0.11$ & $0.91 \pm 0.06$ & 0.84 \\
\hline $1 \mathrm{hr}$ & $0.90 \pm 0.05$ & $0.90 \pm 0.07$ & 0.48 \\
\hline $24 \mathrm{hr}$ & $0.89 \pm 0.08$ & $0.90 \pm 0.06$ & 0.56 \\
\hline $48 \mathrm{hr}$ & $0.87 \pm 0.08$ & $0.88 \pm 0.13$ & 0.99 \\
\hline
\end{tabular}

Values are presented as means \pm standard deviation when appropriate or as median [interquartile range] when the distribution was not normal. There were no significant differences between the groups. $[\mathrm{P}<0.017$ would represent a significant difference between treatment groups taking into account Bonferroni adjustment for multiple measurements.]
Table 5. Anterior cerebral artery flow velocity

\begin{tabular}{cccc}
\hline $\begin{array}{c}\text { Right anterior } \\
\text { cerebral artery }\end{array}$ & Indomethacin & Ibuprofen & $\begin{array}{c}\text { Significance } \\
\text { indomethacin vs. } \\
\text { ibuprofen }(p)\end{array}$ \\
\hline $\begin{array}{c}\text { Systolic velocity } \\
\text { (cm/sec) }\end{array}$ & & & \\
Pre-treatment & $34 \pm 22$ & $30 \pm 10$ & 0.59 \\
$1 \mathrm{hr}$ & $35 \pm 20$ & $27 \pm 12$ & 0.06 \\
$24 \mathrm{hr}$ & $34 \pm 19$ & $28 \pm 8$ & 0.49 \\
$48 \mathrm{hr}$ & $31 \pm 12$ & $31 \pm 10$ & 0.89 \\
Diastolic velocity & & & \\
$\quad(\mathrm{cm} /$ sec) & & & 0.89 \\
Pre-treatment & $1.7[1.2,3.3]$ & $1.7[1.2,3.6]$ & 0.17 \\
$1 \mathrm{hr}$ & $2.4[1.4,3.9]$ & $2.6[1.8,4.8]$ & 0.77 \\
$24 \mathrm{hr}$ & $2.4[0.9,3.5]$ & $2.3[1.8,4.1]$ & 0.45 \\
$48 \mathrm{hr}$ & $2.4[0.9,3.5]$ & $2.0[0.9,5.8]$ & \\
Velocity time & & & 0.69 \\
Integral & & & 0.28 \\
Pre-treatment & $4.7 \pm 3.1$ & $4.6 \pm 2.1$ & 0.87 \\
$1 \mathrm{hr}$ & $4.8 \pm 2.8$ & $4.4 \pm 2.9$ & 0.78 \\
$24 \mathrm{hr}$ & $4.2 \pm 1.8$ & $4.4 \pm 1.8$ & \\
$48 \mathrm{hr}$ & $4.1 \pm 1.0$ & $4.3 \pm 2.8$ & 0.68 \\
Resistance index & & & 0.69 \\
Pre-treatment & $0.91 \pm 0.08$ & $0.90 \pm 0.07$ & \\
$1 \mathrm{hr}$ & $0.90 \pm 0.07$ & $0.85 \pm 0.09$ & \\
$24 \mathrm{hr}$ & $0.88 \pm 0.10$ & $0.85 \pm 0.12$ & 0.82 \\
$48 \mathrm{hr}$ & $0.88 \pm 0.10$ & $0.87 \pm 0.11$ & \\
\hline
\end{tabular}

Values are presented as means \pm standard deviation when appropriate or as median [interquartile range] when the distribution was not normal. There were no significant differences between the groups. $[\mathrm{P}<0.017$ would represent a significant difference between treatment groups taking into account Bonferroni adjustment for multiple measurements.]

with ductal closure, significant only in the indomethacin group. There were no significant differences between the treatment groups for any parameter at any given time.

Longer term outcome. Four indomethacin babies and three ibuprofen infants expired. Of interest, five of the seven infants who expired had NEC at the time of death; one additional infant had had NEC in the past and at the time of death suffered from an intestinal perforation during a rotavirus infection, and the seventh expired on day 4 of life with overwhelming Escherichia coli sepsis. Although there were no differences between the groups in the incidence or severity of NEC (Table 6), the overall incidence of $29 \%$ in the study population is substantially higher than the background incidence in our unit of $15 \%$ in infants of $\leq 1500$-g birth weight (Fig. 2) (16).

There were also no differences between the groups in the incidence or severity of BPD, IVH, and/or ROP (Fig. 2). Subanalysis of the above conditions by grade or severity also showed no significant differences. However, when compared with the underlying incidence in $<1500$-g infants in our department (17), our study babies (both groups combined) had significantly more ROP $(p=0.005)$ and more severe (grade $3-4)$ ROP $(p=0.012)$; more BPD $(p=0.041)$; and more $\operatorname{NEC}(p=0.013)$.

\section{DISCUSSION}

The question as to whether indomethacin or ibuprofen is preferred in the treatment of the persistent PDA remains 
Table 6. Necrotizing enterocolitis patients

\begin{tabular}{lccc}
\hline & Indomethacin & Ibuprofen & Significance $(p)$ \\
\hline Necrotizing enterocolitis [NEC] & & & \\
Incidence (\%) & $7(22 \%)$ & $9(28 \%)$ & 0.829 \\
Bell stage (median, interquartile range) & $3[2.8,3.0]$ & $3[2.0,3.0]$ & 0.521 \\
Perforation & $1(14 \%)$ & $3(33 \%)$ & 0.585 \\
Patent ductus arteriosus treatment [in NEC infants] & $1.6 \pm 1.1$ & $1.6 \pm 1.0$ & 0.985 \\
\# Courses therapy (mn \pm SD) & $1(14 \%)$ & $3(33 \%)$ & 0.585 \\
Surgical ligation & $1(14 \%)$ & $2(22 \%)$ & 1.0 \\
Mortality [in NEC infants] & & \\
\hline
\end{tabular}

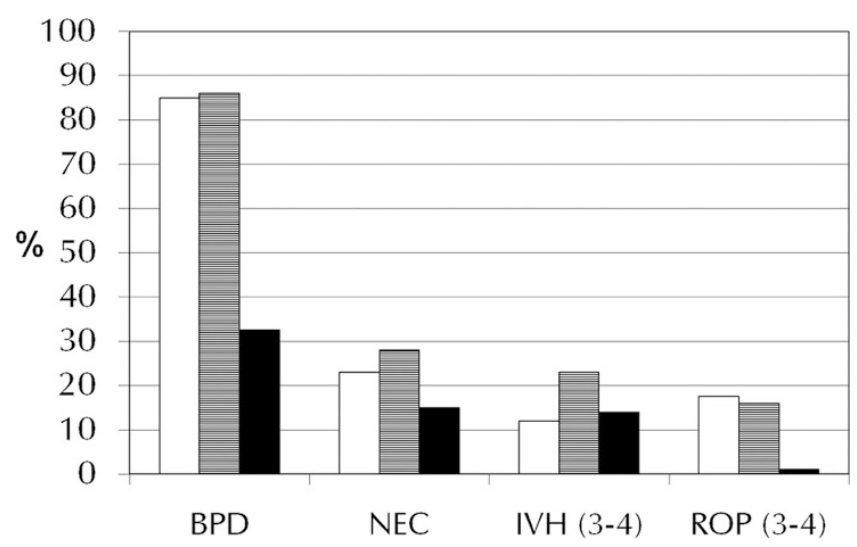

Figure 2. Incidence of major long-term, potentially vascular mediated complications in the continuous indomethacin $\square$ versus ibuprofen background incidence in $\leq 1500$-g infants from our hospital (obtained from national database data) presented for comparison.

controversial. All clinical trials to date concur that the therapeutic efficacy of both drugs for closure of the PDA is similar (18). Several studies have reported that ibuprofen is less nephrotoxic, and a meta-analysis comparing bolus indomethacin with ibuprofen (18) concluded that ibuprofen is associated with lower serum creatinine values, higher urine outputs, less undesirable decreased organ blood flow, and adverse vasoconstrictive effects, potentially bestowing upon it some therapeutic superiority over indomethacin. However, a recent Cochrane review published concurrently analyzed the same data differently and concluded that "based on currently available information, ibuprofen does not appear to confer a net benefit over indomethacin for the treatment of a PDA. We (Cochrane) conclude that indomethacin should remain the drug of choice for the treatment of a PDA" (19).

Both indomethacin and ibuprofen act via inhibition of the cyclo-oxygenase enzyme, presumably both effecting ductal closure via inhibition of prostaglandin synthesis. To what, then, can we ascribe the observed differences in toxicity? Possibly, the differences can be attributed to more selective inhibition of one of the cyclo-oxygenase isoforms, which may, in turn, have more influence on renal function (10). On the other hand, it is also theoretically possible that the differences are not indigenous to the drugs, but rather to the mode of administration. This concept is supported by animal studies, which demonstrate that ibuprofen is, in fact, not exempt from adverse renal effects.

A study in newborn rabbits has revealed that i.v. ibuprofen causes dose-dependent reductions in urine volume, GFR, and renal blood flow, together with an increase in renal vascular resistance and a decrease in urinary sodium excretion (20), similar to those caused by indomethacin. In preterm human neonates, Cataldi et al. (21) have shown that ibuprofen does constitute a risk factor for acute renal failure. In contrast, we and others have shown that continuous indomethacin administration eliminates the changes in cerebral (13), renal and mesenteric (14) blood flow velocity, and in urine output described with bolus indomethacin administration.

Based on the above data, we hypothesized that continuous infusion of indomethacin would minimize any vascular mediated adverse effects and thereby offer similar therapeutic benefits to ibuprofen.

Renal effects. Previous studies, which have compared ibuprofen with bolus indomethacin, have cited either significant indomethacin associated decreases in urine output and increases in serum creatinine levels (6) or a strong trend toward oliguria (22). Others have demonstrated indomethacin-related reductions in mesenteric and renal blood flow velocity (11).

In contrast, in this study, none of the infants developed oliguria and urine output did not decrease significantly in any infants in either group. Serum creatinine levels actually decreased rather than increased over the course of the study in both groups, presumably reflecting improved renal perfusion resulting from ductal closure. Fluid intake was similar in both groups.

GFR of newborns result from carefully balanced vasoconstrictor and vasodilator forces. A significant PDA with a large diastolic run-off can adversely affect this delicate balance. The physiologic response to hypoperfusion would be to increase intrarenal prostaglandin production, resulting in microvascular vasodilation and, thereby, improved renal perfusion. This helps to explain why the neonatal kidney might be particularly sensitive to the adverse effects of cyclo-oxygenase inhibitors, which might impair this natural defense mechanism.

Direct measurements of GFR are time-consuming, expensive, and generally require long-term urine collection, all of which are unpractical in most NICU situations. Thus, in lieu of direct measurements, we used the Schwartz formula, a calculated estimate of GFR considered to be clinically useful in infants (23).

Finally, both indomethacin and ibuprofen can have effects on renal function beyond these vasoactively mediated. Inhibition of prostaglandin synthesis can reduce natriuresis and increase sodium reabsorption. In fact, Zanardo et al. (24) noted that both indomethacin (bolus) and ibuprofen significantly reduced urinary sodium. Thus, it is noteworthy that we 
found no effect on the fractional excretion of sodium either within or between groups, indicating that the delicate neonatal renal balance was maintained in both groups of study infants.

Ductal response. No baby in our study who responded with complete ductal closure reached surgical ligation. This observation has not, to the best of our knowledge, been previously reported. Some infants did develop recurrences, but all responded to a second course of medical therapy. The converse, however, has been reported. Keller and Clyman(25) noted that newborns $<28$-wk gestational age with recurrent, symptomatic PDA who had persistent Doppler evidence of ductus flow after completion of their initial indomethacin course rarely respond to subsequent courses of indomethacin therapy.

It is worth mentioning that $15 \%$ of our total babies (groups combined) whose PDA closed initially suffered a recurrence, and $67 \%$ of those who partially constricted, reopened. These percentages are consistent with the data reported by Weiss et al. (26), who found that if no luminal patency was detected on the posttherapy Doppler study, the chance of later reopening is $<20 \%$ for infants $<27$-wk gestation. However, if evidence of luminal patency persisted, $>90 \%$ of infants eventually had some degree of ductal reopening.

In all previously published studies, comparing ibuprofen with indomethacin, no differences in ductal closure rates were observed, and our data are consistent with previous studies in this regard. Our study, however, was not powered to detect differences in therapeutic efficacy and as such, trying to reach any conclusions about the relative efficacy of either drug in closing the ductus is clearly beyond the scope of this study.

Other vascular-mediated effects. We found no differences between treatment groups in any of the blood flow velocity parameters studied. Although blood flow velocity is not a direct measurement of blood flow, serial flow velocities do reflect changes in blood flow $(27,28)$. Furthermore, as Doppler ultrasound is portable point of care, noninvasive, and reproducible, it has become a standard tool to estimate blood flow in prematures (29). For all these reasons, it is the best-suited method for comparing relative changes over time in response to therapeutic interventions. Although MRS may provide a more accurate assessment of blood flow, it is not a bedside tool, and thus not a feasible approach for repetitive measurements of blood flow in sick, ventilated premature neonates.

Perfusion of distal organs, impaired secondary to diastolic run-off, may potentially be exacerbated by vasoconstrictive effects of therapy. Because normal postnatal dynamics are characterized by physiologic increases in blood flow, these organs are extremely susceptible to reductions in blood flow, which, in turn, can increase susceptibility to NEC, renal hypoperfusion, IVH, and/or ROP. We found no difference in the incidence of any of these vascular-mediated conditions between our two groups.

The combination of NEC and a treated PDA was especially devastating in our study. Seventy-one percent of our study mortality was attributable to the NEC/medically treated PDA combination. We speculate that the effects may be synergistic, with decreased local perfusion possibly exacerbated by treatment-induced vasoconstriction, contributing to intestinal ischemia. However, it is also possible that inflammatory mediators involved in both conditions potentiate one another contributing to disproportionately severe intestinal tissue damage.

One limitation of this study is that it encompassed only the first course of therapy. Babies randomized to ibuprofen who were retreated received indomethacin the second time around, as this remains the standard of care in our institution. Thus, these babies were exposed to both drugs. Although this would not impact upon the initial effects, it might affect the analysis of longer term complications, e.g., incidence and severity of ROP, NEC, and IVH, possibly masking intergroup differences. It is also possible that we did not find any significant differences, because our study was underpowered to demonstrate noninferiority.

In summary, although ibuprofen minimizes adverse renal effects seen following bolus indomethacin, concerns regarding the long-term safety and side effects of ibuprofen remain. In two trials $(5,6)$, the proportion of infants who developed chronic lung disease was significantly higher with ibuprofen than with indomethacin. Furthermore, ibuprofen is $99 \%$ protein bound, and in vitro studies suggest that it may displace bilirubin from albuminbinding sites, thereby increasing the risk for kernicterus $(30,31)$. Although preliminary in vivo studies (Van Overmeire B, Pediatric Academic Societies, May 2004, San Francisco, California) show no increase in free bilirubin given therapeutic doses of ibuprofen, there is, as yet, no definitive answer on this issue. In addition, the tris-hydroxyamino-methane form of ibuprofen has been associated with pulmonary hypertension (32) and NEC (19). Finally, studies have yet to determine the long-term effects of ibuprofen.

Indomethacin, on the other hand, has been used to treat premature neonates for many years. Other than transient vasoconstrictive effects, including occasional spontaneous intestinal perforations, no long-term toxicity of indomethacin has been noted. In this study, we have demonstrated that ibuprofen offered no advantage over indomethacin given by continuous infusion with respect to decreased urine output, renal function or renal, mesenteric, or cerebral artery vasoconstriction. Thus, if, as described, we are able to eliminate the adverse effects, indomethacin would remain for many the therapy of choice for the premature with PDA. Further clinical trials using continuous indomethacin would need to be performed to confirm these findings.

Acknowledgments. We thank the NICU nurses. Without their cooperation, patience, and proficiency, we would not have been able to complete the study. Also we thank Mr. and Mrs. Stephen Hammerman and the Hammerman-Fisch Foundation.

\section{REFERENCES}

1. Austin NC, Pairaudeau PW, Hames TK, Hall MA 1992 Regional cerebral blood flow velocity changes after indomethacin infusion in preterm infants. Arch Dis Child 67:851-854

2. Van-Bel F, Van-de-Bor M, Stijnen T, Baan J, Ruys JH 1989 Cerebral blood flow velocity changes in preterm infants after a single dose of indomethacin: duration of its effect. Pediatrics 84:802-807

3. Van-Bel F, Van-Zoeren D, Schipper J, Guit GL, Baan J 1990 Effect of indomethacin on superior mesenteric artery blood flow velocity in preterm infants. J Pediatr 116:965-970

4. Van-Bel F, Guit GL, Schipper J, van-de-Bor M, Baan J 1991 Indomethacin-induced changes in renal blood flow velocity waveform in premature infants investigated with color Doppler imaging. J Pediatr 118:621-626 
5. Van Overmeire B, Follens I, Hartmann S, Creten WL, Van Acker KJ 1997 Treatment of patent ductus arteriosus with ibuprofen. Arch Dis Child Fetal Neonatal Ed 76:F179-F184

6. Van Overmeire B, Smets K, Lecoutere D, Van de Broek H, Weyler J, Degroote K, Langhendries JP 2000 A comparison of ibuprofen and indomethacin for closure of patent ductus arteriosus. N Engl J Med 343:674-681

7. Patel J, Roberts I, Azzopardi D, Hamilton P, Edwards D 2000 Randomized doubleblind controlled trial comparing the effects of ibuprofen with indomethacin on cerebral hemodynamics in preterm infants with patent ductus arteriosus. Pediatr Res 47:36-42

8. Mosca F, Bray M, Lattanzio M, Fumagalli M, Tosetto 1997 Comparative evaluation of the effects of indomethacin and ibuprofen on cerebral perfusion and oxygenation in preterm infants with patent ductus arteriosus. J Pediatr 131:549-554

9. Lago P, Bettiol T, Salvadori S, Pitassi I, Vianello A, Chiandetti L, Saia OS 2002 Safety and efficacy of ibuprofen versus indomethacin in preterm infants treated for patent ductus arteriosus: a randomised controlled trial. Eur J Pediatr 161:202-207

10. Su PH, Chen JY, Su CM, Huang TC, Lee HS 2003 Comparison of ibuprofen and indomethacin therapy for patent ductus arteriosus in preterm infants. Pediatr Int 45:665-670

11. Pezzati M, Vangi V, Biagiotti R, Bertini G, Cianciulli D, Rubaltelli F 1999 Effects of indomethacin and ibuprofen on mesenteric and renal blood flow in preterm infants with patent ductus arteriosus. J Pediatr 135:733-738

12. Aranda JV, Thomas R 2006 Intravenous Ibuprofen for preterm newborns. Semin Perinatol 30:114-120

13. Hammerman C, Glaser J, Schimmel MS, Ferber B, Kaplan M, Eidelman AI 1995 Continuous vs. bolus indomethacin: effects on cerebral blood flow. Pediatrics 95:244-248

14. Christmann V, Liem KD, Semmekrot BA, van de Bor M 2002 Changes in cerebral, renal and mesenteric blood flow velocity during continuous and bolus infusion of indomethacin. Acta Paediatr 91:440-446

15. Vane JR, Botting RM 1997 Mechanism of action of anti-inflammatory drugs. In: Sinzinger H, Samuelsson B, Vane JR, Paoletti R, Ramwell P, Wong PY (eds). Recent Advances In Prostaglandin, Thromboxane, and Leukotriene Research. Advances in Experimental Medicine and Biology. Vol. 433. New York: Plenum Press, pp $137-138$

16. Bin-Nun A, Bromiker R, Wilschanski M, Kaplan M, Rudensky B, Caplan M, Hammerman C 2005 Oral probiotics prevent necrotizing enterocolitis in very low birth weight neonates. J Pediatr 147:192-196

17. Israel Neonatal Network and the ICDC 2004 Very low birth weight database. National annual report, in collaboration with the Israel Neonatal Network and the ICDC

18. Thomas RL, Parker GC, Van Overmeire B, Aranda JV 2005 A meta-analysis of ibuprofen vs indomethacin for closure of patent ductus arteriosus. Eur J Pediatr 164:135-140
19. Ohlsson A, Walia R, Shah S 2005 Ibuprofen for the treatment of patent ductus arteriosus in preterm and/or low birth weight infants. Cochrane Database Syst Rev CD003481

20. Chamaa NS, Mosig D, Drukker A, Guignard J-P 2000 The renal hemodynamic effects of ibuprofen in the newborn rabbit. Pediatr Res 48:600-605

21. Cataldi L, Leone R, Moretti U, De Mitri B, Fanos V, Ruggeri L, Sabatino G, Torcasio F, Zanardo V, Attardo G, Riccobene F, Martano C, Benini D, Cuzzolin L 2005 Potential risk factors for the development of acute renal failure in preterm newborn infants: a case-control study. Arch Dis Child Fetal Neonatal Ed 90: F514-F519

22. Su BH, Lin HC, Chiu HY, Hsieh HY, Chen HH. Comparison of ibuprofen and indomethacin for early-targeted treatment of patent ductus arteriosus in extremely premature infants: a randomized controlled trial. Arch Dis Child Fetal Neonatal Ed, in press

23. Schwartz GJ, Brion LP, Spitzer A 1987 The use of plasma creatinine concentration for estimating glomerular filtration rate in infants, children and adolescents. Pediat Clin North Am 34:571-590

24. Zanardo V, Vedovato S, Lago P, Piva D, Faggian D, Chiozza L 2005 Effects of Ibuprofen and Indomethacin on urinary antidiuretic hormone excretion in preterm infants treated for patent ductus arteriosus. Fetal Diagn Ther 20:534-539

25. Keller RL, Clyman RI 2003 Persistent doppler flow predicts lack of response to multiple courses of indomethacin in premature infants with recurrent patent ductus arteriosus. Pediatrics 112:583-587

26. Weiss H, Cooper B, Brook M, Schlueter M, Clyman R 1995 Factors determining reopening of the ductus arteriosus after successful clinical closure with indomethacin. J Pediatr 127:466-471

27. Briscoe DM, Hoffer FA, Tu N, Harmon WE 1993 Duplex doppler examination of renal allografts in children: correlation between renal blood flow and clinical findings. Pediatr Radiol 23:365-368

28. Alwaidh MH, Cooke RW, Judd BA 1998 Renal blood flow velocity in acute renal failure following cardiopulmonary bypass surgery. Acta Paediatr 87:644-649

29. Luciano R, Gallini F, Romagnoli C, Papacci P, Tortorolo G 1998 Doppler evaluation of renal blood flow velocity as a predictive index of acute renal failure in perinatal asphyxia. Eur J Pediatr 157:656-660

30. Ahlfors CE 2004 Effect of ibuprofen on bilirubin-albumin binding. J Pediatr 144:386-388

31. Cooper-Peel C, Brodersen R, Robertson A 1996 Does ibuprofen affect bilirubinalbumin binding in newborn infant serum? Pharmacol Toxicol 79:297-299

32. Gournay V, Roze JC, Kuster A, Daoud P, Cambonie G, Hascoet JM, Chamboux C, Blanc T, Fichtner C, Savagner C, Gouyon JB, Flurin V, Thiriez G 2004 Prophylactic ibuprofen versus placebo in very premature infants: a randomized, double-blind, placebo-controlled trial. Lancet 364:1939-1944 